\title{
NOTICIARIO
}

\section{LA SECUENCIA CULTURAL DE LAS PRIMERAS SOCIEDADES PRODUCTORAS EN EXTREMADURA: UNA DATACIÓN ABSOLUTA DEL YACIMIENTO DE LOS BARRUECOS (MALPARTIDA DE CÁCERES, CÁCERES)}

\author{
THE CULTURAL SEQUENCE OF THE FIRST PRODUCTIVE SOCIETIES IN SPANISH \\ EXTREMADURA: A RADIOCARBON DATE FROM "LOS BARRUECOS" SITE \\ (MALPARTIDA DE CÁCERES, CÁCERES)
}

ENRIQUE CERRILLO CUENCA $(*)$

ALICIA PRADA GALLARDO $(* *)$

ANTONIO GONZÁLEZ CORDERO (**)

FRANCISCO JAVIER HERAS MORA $(* * * *)$
Key words: Spanish Extremadura. Tagus Valley. Early Neolithic. Radiocarbon date.

\section{INTRODUCCIÓN}

Presentamos en este trabajo un avance al estudio del yacimiento de Los Barruecos (Malpartida de Cáceres), tras la campaña desarrollada en 2001; sin duda, el interés de ésta reside en el estudio de su primer nivel de ocupación que abiertamente permite hablar de poblamiento al aire libre desde las fases más antiguas del Neolítico.

El conjunto de dataciones que se han dado a conocer recientemente en el Alentejo (Diniz 2001), las provincias de Soria (Kunst y Rojo 1999), Palencia (Delibes y Zapatero 1996), Segovia (Estremera 1999) y Toledo (Bueno et al. 1999) demuestra la vitalidad que ha adquirido el estudio del Neolítico en el interior peninsular. Dentro de ese panorama, la datación que presentamos y su contexto vienen a ser, por tanto, un enlace cronológico entre situaciones culturales similares que se observan en Andalucía Occidental, la fachada atlántica y la Meseta. Espacios, que una vez relacionados, invitan a revisar adecuadamente los marcos conceptuales que se habían cimentado en el teórico cariz retardatario del "Neolítico interior".

En lo referente al periodo que nos ocupa y su in- 
vestigación, se están documentando en Extremadura un número considerable de yacimientos en los últimos años (González Cordero 1999b; González Cordero y Cerrillo Cuenca 2001), pero se hacía necesario reconducir los esfuerzos a la obtención de datos de excavación que completasen, con fechas y analíticas, el variado sistema de poblamiento que hoy conocemos. El yacimiento de Los Barruecos, donde intuíamos una potente estratificación, se perfilaba como un lugar idóneo para obtener materiales contextualizados, que parcamente ofrecían otros yacimientos, y al mismo tiempo definir mejor la secuencia ocupacional de uno de los yacimientos más completos e interesantes de la cuenca media del Tajo. Hay que recordar como se habían reconocido cerámicas impresas neolíticas en el transcurso de la excavación de otros tres yacimientos cacereños. $\mathrm{La}$ cueva de Boquique, aunque estratigráficamente alterada, mantenía en su nivel de base algunas cerámicas (Almagro-Gorbea 1977) que servían para ratificar la ocupación neolítica del yacimiento casi testimonialmente (Fernández-Posse 1982). El Conejar había ofrecido gran cantidad de cerámicas impresas (Cerrillo Martín de Cáceres 1983; Sauceda 1984; González Cordero 1996; Cerrillo Cuenca 1999); pero tras varias campañas de excavación en 1916, 1981, 1982-1983, 2000 y 2001 se puede afirmar con seguridad que únicamente ha llegado in situ hasta nosotros una brecha caliza con material epipaleolítico. Y por último en los dos poblados calcolíticos del Cerro de la Horca y Castillejos II en Plasenzuela, donde tras las excavaciones sistemáticas desarrolladas por uno de nosotros, únicamente un corte, el B-5 del Cerro de la Horca, ofreció un nivel con cerámicas impresas conservado bajo una capa estéril (González Cordero et al. 1988).

\section{LA INTERVENCIÓN DE 2001}

Con el objetivo de paliar la escasez de datos paleo-ambientales y dataciones radiocarbónicas de que adolecen las épocas que nos ocupan en Extremadura, entre agosto y septiembre de 2001 intervinimos nuevamente en el yacimiento de Los Barruecos. Es necesario recordar que a lo largo de la década de los años 80 el Museo de Cáceres e Isabel Sauceda, posteriormente, desarrollaron seis campañas de excavación en el yacimiento, parcialmente publicadas en dos breves trabajos (Sauceda 1986 y 1991). Centrados en diversos puntos del yacimiento, lo cierto es que los trabajos de excavación sólo

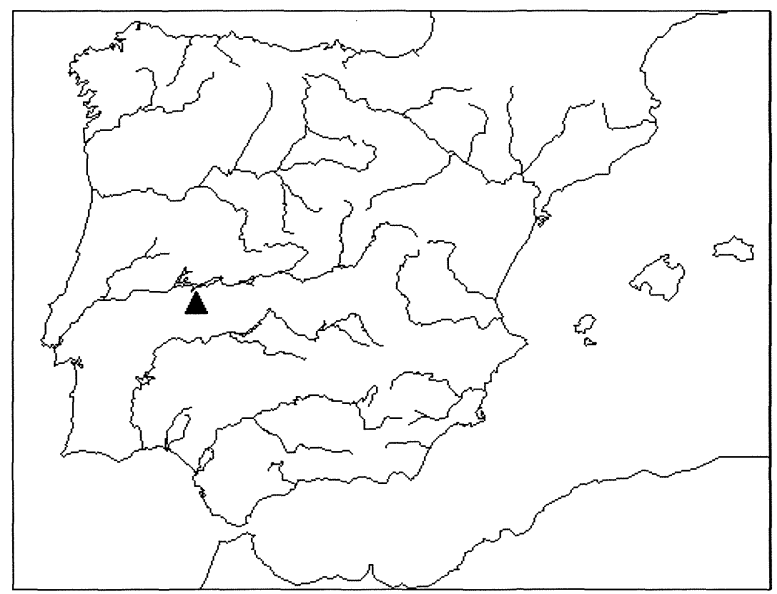

Fig 1. Situación del yacimiento de Los Barruecos (Malpartida de Cáceres) en la Península Ibérica.

habían terminado por ofrecer tres aparentes fases vertebradas en Calcolítico Inicial, Pleno y Final (Sauceda 1991: 34-39) aisladas a partir de determinados criterios ergológicos de la cerámica. Posteriores trabajos (González Cordero 1996: 700) han puesto de manifiesto cómo bajo una perspectiva tipológica el yacimiento muestra una amplia secuencia de ocupación no valorada en sus justos términos.

El yacimiento se describe como una pequeña meseta localizada entre los bloques graníticos que resaltan sobre las zonas pizarrosas próximas, elevándose a unos 320 metros sobre el nivel del mar. Todo este emplazamiento ofrece dos líneas de muralla que aprovechan los bolos del terreno para cerrar un espacio en el que se han centrado nuestros trabajos. Paralelamente existen algunos abrigos próximos con evidencias de poblamiento unos y grafías otros; son precisamente estos últimos elementos, grabados y pinturas, los que más posibilidades de relación ofrecen al estar localizadas en el propio hábitat (González Cordero 1999a: 192-193).

El entorno ofrece elementos que hablan de una intensa organización paisajística durante distintos periodos de la Prehistoria Reciente como indican los grabados y pinturas recientemente recopilados en un catálogo (Sauceda 2001), pero también cámaras megalíticas que se reparten desigualmente en un radio de 5 kilómetros, algunos de ellos ya conocidos por las excavaciones de M. Almagro Basch en la finca de Hijadilla (Almagro Basch 1962; Bueno 2000: 47), o por prospección, como el túmulo de la Redondilla (Bueno 1994: 68), junto a otros inéditos. Por último habría que completar esta breve re-

T. P., 59, n. $^{\circ} 2,2002$ 
ferencia de sitios con algunos puntos en los que aparecen evidencias de hábitats de cronologías prehistóricas escasamente determinadas, en la que Los Barruecos se muestra como la evidencia de poblamiento más notable.

La intervención de 2001 se centró en definir la estratigrafía del yacimiento, pero especialmente en reconocer posibles hiatus de poblamiento que se suponían a partir del estudio de las campañas previas. Para ello planteamos un único corte, que con una extensión de $12 \mathrm{~m}^{2}$ permitiese alcanzar la roca natural, donde, según la información que poseíamos, se localizaban estructuras de hábitat a las que se asociaban cerámicas impresas a unos 2,5 metros de profundidad. Sin embargo, este corte apareció bastante alterado a consecuencia de un agujero practicado en el terreno de unos 2 metros de diá-metro y que a juzgar por sus materiales (ánforas Dressel 1, bordes vueltos y un regatón de hierro) se sitúa en torno a los siglos II-I a.C. Por tanto, comprobamos parcialmente en los bordes del corte una sucesiva superposición de suelos adscribibles al Bronce Inicial y al Calcolítico; el reducido espacio que nos restó para comprobar la estratigrafía permitió observar como un paquete de elementos neolíticos aparecían sellados por una capa de descomposición de granitos que prácticamente se mostraba estéril.

Alentados por la presencia de este último nivel de ocupación, se optó en los últimos días de la campaña de excavación por efectuar sondeos en la base de uno de los cortes de la campaña de 1988 (Sauceda 1991: 31, fig. 4), en los que no se había alcanzado la roca natural y donde una serie de estructuras garantizaban que el nivel arqueológico no había sido alterado. El objetivo era comprobar mejor la presencia de un horizonte con cerámicas impresas que habíamos documentado en el sondeo anterior, y que también conocíamos a partir de los materiales depositados en el Museo de Cáceres.

Se excavaron un total de $10 \mathrm{~m}^{2}$, que ofrecieron la estratigrafía que describimos a continuación. El suelo de la ocupación previa, cuya adscripción cultural esperamos aclarar en el transcurso de la próxima campaña, se mostraba como una capa de color grisáceo y textura compacta que daba paso a un nivel de tierra suelta y color claro producto de la descomposición del granito. Este nivel, prácticamente estéril, ofrecía a cierta profundidad un conjunto de materiales arrastrados. Por último en la parte Norte, corte 2-c, del espacio excavado localizamos una zanja de sección en $\mathrm{V}$, que tras una valoración inicial de sus materiales podemos ads- cribir al Neolítico Final. La zanja, que ofrecía abundante relleno de restos faunísticos y material cerámico, estuvo amortizada durante la ocupación calcolítica, como lo demuestra el hecho de que aparezca por encima de ella el suelo de ocupación calcolítico. Por último en la misma zona, en los cortes 2-a y 2-b, documentamos un silo del Neolítico Antiguo, que hemos podido datar en el tránsito del VI al V milenio cal BC.

\section{UNA ESTRUCTURA DE ALMACENAJE DEL NEOLÍTICO ANTIGUO}

Pese al estado aún embrionario de nuestro conocimiento de este yacimiento, estamos en condiciones de presentar la estructura anteriormente comentada y los materiales asociados a ella, puesto que creemos que resultan de interés a la hora de aportar datos sobre la ocupación neolítica del interior, y efectivamente tratar de relacionar una estructura de almacenaje como la que presentamos con todo un trasfondo de estrategias de producción alimenticia.

La excavación de esta estructura, nos deparó en un primer momento una capa de tierra oscura, vegetal, con presencia de algunos materiales cerámicos y escasa industria lítica. Bajo esta última unidad se localizaba la cubierta de la fosa formada a partir de cuarzos y granitos de pequeño tamaño en el que se encontraban amortizados algunos fragmentos de cerámica; todo ello daba paso al relleno de esta estructura, de unos 70 centímetros de diámetro, que había sido excavada en la capa de descomposición del granito previa a la roca madre. El relleno de esta fosa estaba compuesto por arenas de color oscuro, donde los materiales arqueológicos resultaban escasos. Fue precisamente en el contacto entre estas unidades donde obtuvimos varios gránulos de carbón que corresponden a la datación por AMS y que sitúa su momento de uso en el $6060 \pm$ $50 \mathrm{BP}$.

El conjunto de materiales, que presentamos se encontraba amortizado en las dos capas que componían la cubrición del silo. El material cerámico es el más numeroso e incluye un conjunto de piezas en el que dominan las incisiones y las acanaladuras, aunque también existe un reducido número de impresas con matrices distintas. Destacan además las cerámicas decoradas con cordones aplicados, y que actúan como elemento organizativo de la decoración. Las formas suelen ser simples, e incluyen 


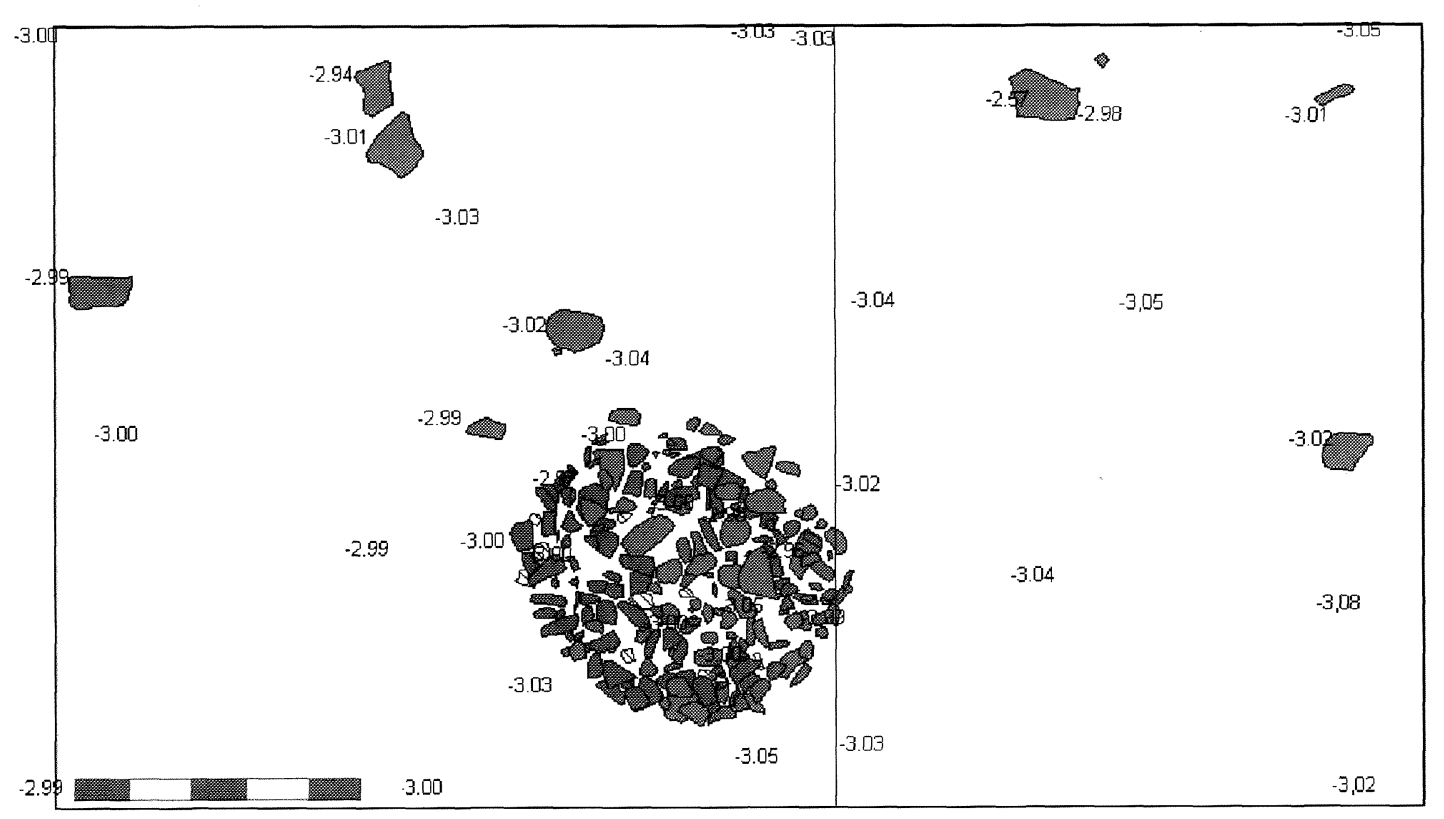

$\mathrm{N}$

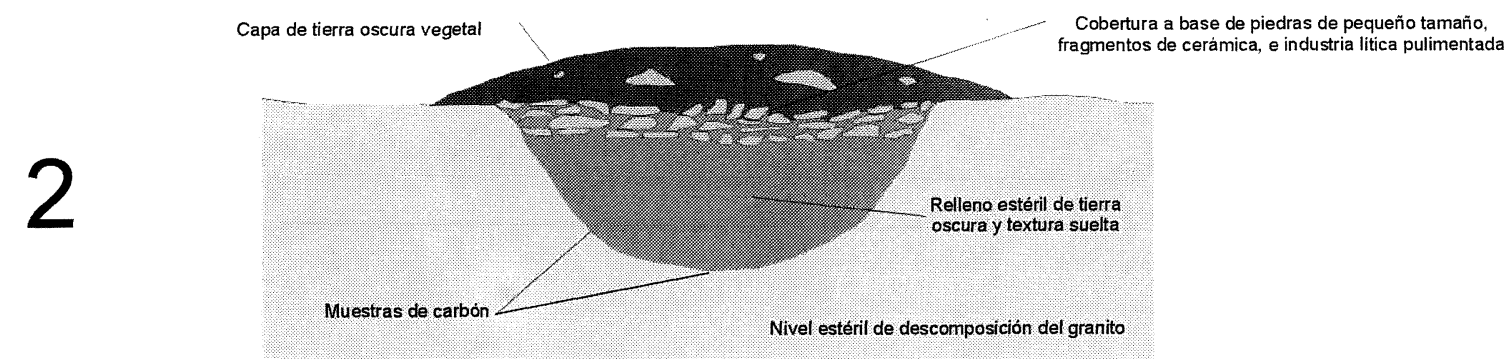

Fig. 2. 1. Planta de las cuadrículas 2-a y 2-b en el momento de la excavación de la cubierta del silo. 2. Reconstrucción de la sección del silo indicando las distintas unidades reconocidas.

cuencos y vasos donde predomina la tendencia abierta. Hemos recogido estas variables y su presencia en la estructura que nos ocupa en las tablas 1 y 2 , aunque la estadística que incluimos puede verse modificada sensiblemente con la excavación de otras áreas de actividad en próximas campañas.

\begin{tabular}{|l|l|}
\hline Fragmentos lisos & Fragmentos decorados \\
\hline $88,8 \%$ & $11,2 \%$ \\
\hline Tratamiento a la almagra & Sin tratamiento a la almagra \\
\hline $2,1 \%$ & $97,9 \%$ \\
\hline Con elementos de prensión & Sin elementos de prensión \\
\hline $2,6 \%$ & $97,4 \%$ \\
\hline Formas de tendencia abierta & 1 ormas de tendencia cerrada \\
\hline $78,3 \%$ & $21,7 \%$ \\
\hline rragmentos inventariados & 1 ragmentos no in ventariados \\
\hline $15,2 \%$ & $84,8 \%$ \\
\hline
\end{tabular}

Tabla 1. Variables más indicativas del conjunto cerámico estudiado en el silo. Todos los porcentajes han sido calculados sobre el total de la muestra (223 fragmentos), excepto las formas.
En referencia a la industria lítica, es reseñable la escasez de sílex, con la presencia de varias lascas internas y una laminita de dorso abatido con muesca en el extremo distal izquierdo; ello se ve completado con una buena variedad de pequeñas lascas de cuarzo sin retocar. En cuanto a los elementos pulimentados, únicamente hay que señalar una azuela de gabro fragmentada, de sección redonda, localizada en la cubierta de material que tapaba el silo. Por último, en la misma estructura recogimos otros materiales alóctonos como pizarras con evidencias de uso y un canto trabajado en cuarcita. Dos molederas de granito fragmentadas, completan el conjunto de materiales recuperados.

Estos materiales suponen un punto de partida para empezar a contextualizar de un modo más certero otras evidencias arqueológicas similares de la zona que estudiamos. Así proponemos que conjuntos de cerámicas, como los de São Pedro de 

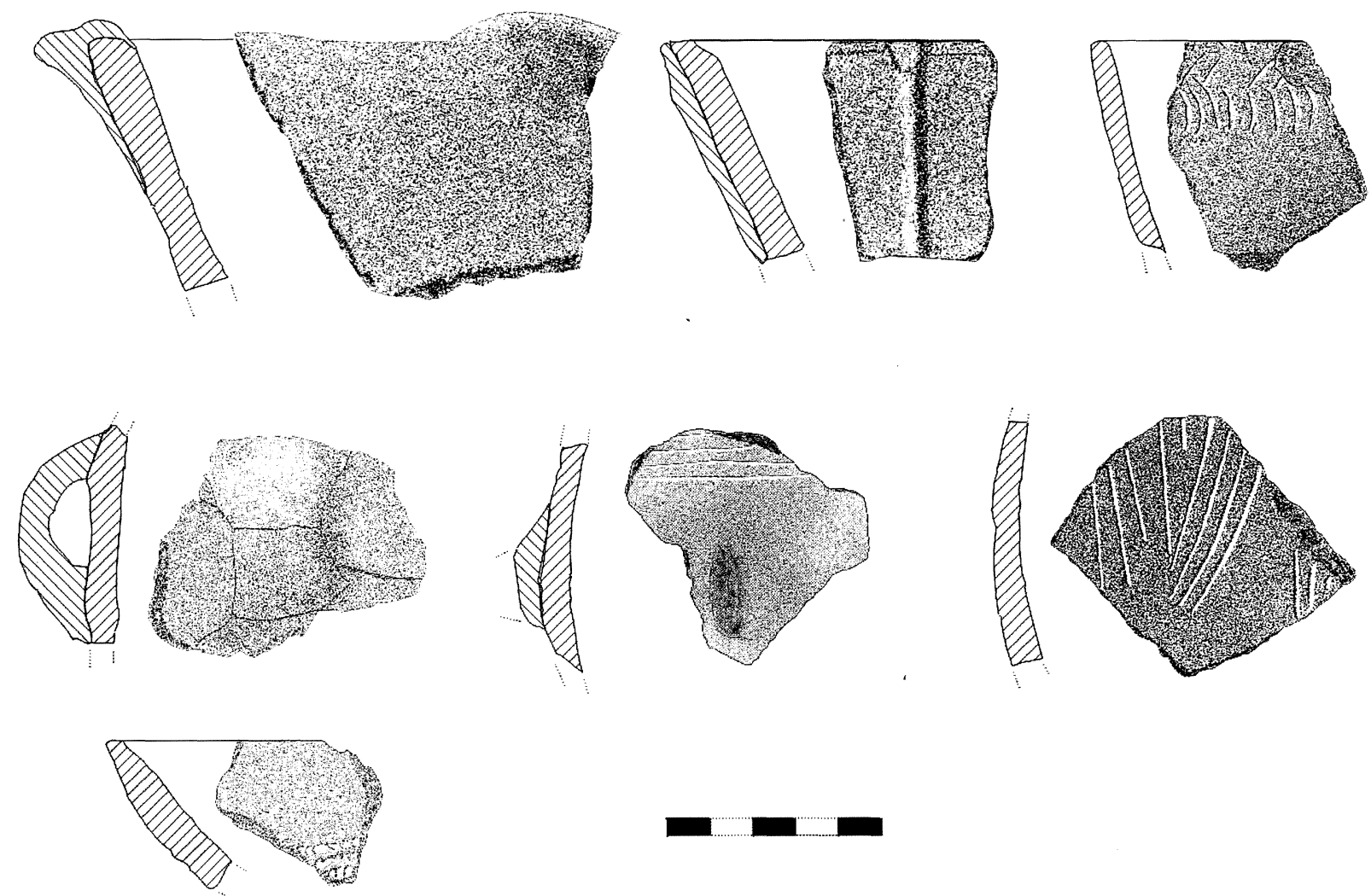

Fig. 3. Materiales cerámicos más representativos recogidos en la cubierta del silo.

Canaferrim (Simões 1999), con el que las cerámicas de Los Barruecos guardan una importante similitud, las de Valada do Mato (Diniz 2000) o las de La Vaquera en Segovia (Estremera 1999), se encuadran en un mismo contexto ahora refrendado por dataciones absolutas (Tab. 3). Este marco cronológico y cultural común, teniendo en cuenta la evolución del Neolítico a nivel peninsular, es el de la paulatina disminución de las cerámicas cardiales en el contexto arqueológico, dando paso a otras técnicas más difundidas como otros tipos de impresión; de forma que los conjuntos de impresas con la técnica de boquique, numerosos en la región, se puedan situar a lo largo del V milenio Cal BC. Sin duda, este intento de seriación deberá confrontarse con el conocimiento de nuevos yacimientos, pero también con la valoración de esta propuesta a una escala espacial conveniente. Por último, hay que resaltar la fecha de los enterramientos del Neolítico Antiguo de Nossa Señora das Lapas (Ooesterbeck 1993: 53) que nos remiten al uso funerario de las cuevas en este mismo momento sin salir de la cuenca del Tajo.
Suponemos que la funcionalidad de esta estructura es la de un espacio de almacenamiento de grano o de algún material perecedero, como se conocen en otras épocas en toda la Península, pero de las que ya hay pruebas en los mismos momentos, concretamente en el yacimiento de la Deseada (Madrid) (Díaz del Río y Consuegra 1999: 253), donde se excavaron estructuras muy semejantes a la que presentamos. Recientemente se han documentado evidencias de concentración de cereal en la cueva de El Conejar, actividad que sólo podemos relacionar de un modo muy parcial, puesto que gran parte del sedimento original de dicha cueva se encuentra seriamente alterado. Las excavaciones desarrolladas en la cueva dentro del Proyecto "Vendimia-Los primeros pobladores de Extremadura" han ofrecido un importante conjunto de semillas brechificadas en un bloque calizo descontextualizado que tras su análisis carpológico se corresponden con Triticum aestivum/durum del tipo compactum y triticum diccocum. Pese al revuelto parcial de la cavidad, hay que hacer notar que la mayor parte de los materiales pueden englobarse en momentos 


\begin{tabular}{|l|l|l|l|l|}
\hline Sigla & Fragmento & \multicolumn{1}{|c|}{$\begin{array}{c}\text { Tratamiento } \\
\text { superficial }\end{array}$} & \multicolumn{1}{|c|}{ Técnicas decorativas } & \multicolumn{1}{c|}{$\begin{array}{c}\text { Elemento de prensión y } \\
\text { suspensión }\end{array}$} \\
\hline D-5000 & Borde & Alisado & Cordón liso & \\
\hline D-5002 & Borde & Alisado & & Mamelón \\
\hline D-5003 & Asa & Alisado & & Asa acintada \\
\hline D-5004 & Pared & Alisado & Acanalada & Arranque de asa \\
\hline D-5005 & Pared & Alisado & Acanalada & \\
\hline D-5006 & Borde & Alisado & Acanalada, puntos impresos & Arranque de asa \\
\hline D-5007 & Pared & Alisado & Acanalada & \\
\hline D-5009 & Pared & Alisado & & Asa tubular \\
\hline D-5010 & Borde & Alisado & Incisa & \\
\hline D-5011 & Borde & Alisado & Cordón sobre el labio, incisa & \\
\hline D-5013 & Borde & Alisado & Apliques, impresa & \\
\hline D-5021 & Borde & Alisado & Boquique & \\
\hline D-5022 & Borde & Espatulada & Series de ungulaciones & \\
\hline D-5025 & Pared & Alisado & Puntos impresós & \\
\hline D-5026 & Borde & Alisado & Acanalada & \\
\hline D-5027 & Borde & Alisado & Cordón liso & \\
\hline D-5029 & Borde & Alisado & Cordón liso & Asa tubular \\
\hline D-5033 & Pared & Alisado & & \\
\hline
\end{tabular}

Tabla 2. Atributos más representativos de las cerámicas decoradas y con elementos de prensión localizados en la estructura datada.

del Neolítico Antiguo/Antiguo Evolucionado, y estarían hablando de un hecho interesante como es la acumulación de cereal en cavidades, donde se hace inevitable citar los trabajos de la Cova de l'Or (Hopf 1966), pero también los cereales documentados en el Buraco da Pala (Sanches 2000: 194). En el caso de Los Barruecos, esperamos que los análisis que realiza Dña. Ana Arnanz, del Laboratorio de Arqueobotánica del CSIC, confirmen la presencia en la estructura que nos ocupa de restos carpológicos.

\section{SOBRE LA TRAYECTORIA DE LAS PRIMERAS SOCIEDADES PRODUCTORAS DEL CENTRO-OESTE PENINSULAR}

Aparte de los contextos datados recientemente, las regiones interiores de la Península ofrecían hasta mediados de los ochenta (Municio 1988) un reducido conjunto de yacimientos neolíticos reconocidos como tales. Por citar algunos de ellos, las cuevas de la Nogalera (Municio y Ruiz-Gálvez
1986) o el Aire de Patones (Fernández-Posse 1980), la Peña del Bardal de Diego Álvaro (Gutiérrez Palacios 1966) o el cerro del Berrueco (Maluquer de Motes 1957), donde a partir de ciertos materiales de superficie era posible situar algunas cerámicas decoradas dentro de los esquemas decorativos propios del Neolítico (Municio 1988: 308). En el caso de Extremadura es la década de los años ochenta la que ha permitido reconocer un buen número de estaciones repartidas por las cuencas hidrográficas del Tajo y Guadiana, algunas de ellas consagradas en la bibliografía como Boquique (Bosch Gimperà 1915-1920; Rivero 1972-73; Almagro-Gorbea 1977; Fernández-Posse 1982), El Conejar (del Pan 1917; Cerrillo Martín de Cáceres 1983; Sauceda 1984; Cerrillo Cuenca 1999), el Cerro de la Horca (González Cordero et al. 1991) o la cueva de la Charneca (Enríquez 1986). Sin embargo, a medida que nuestros trabajos se han incrementado en el territorio el número de yacimientos se ha visto significativamente aumentado, como en los casos de Campo Arañuelo (González Cordero 1999b) o la Vera (González Cordero y Cerrillo Cuenca 2001). 


\begin{tabular}{|c|c|c|c|c|c|c|}
\hline Yacimiento & $\begin{array}{l}\text { Ref. } \\
\text { Bibliográfica }\end{array}$ & $\begin{array}{l}\text { Material } \\
\text { datado }\end{array}$ & $\begin{array}{l}\text { Ref. } \\
\text { Laboratorio }\end{array}$ & \begin{tabular}{|l|}
$\begin{array}{l}\text { Fecha } \\
\text { (BP) }\end{array}$ \\
\end{tabular} & $\begin{array}{l}\text { Intercepciones } \\
1 \sigma \text { (Cal BC) }\end{array}$ & $\begin{array}{l}\text { Intercepciones } \\
2 \sigma \text { (Cal BC) }\end{array}$ \\
\hline $\begin{array}{l}\text { Cueva de la } \\
\text { Vaquera }\end{array}$ & Estremera 1999 & i? & GrN-22932 & $6120 \pm 160$ & $5260-4840$ & $5500-4600$ \\
\hline $\begin{array}{l}\text { São Pedro de } \\
\text { Canaferrim }\end{array}$ & Simões 1997 & Carbón & ICEN-1152 & $6070 \pm 70$ & $\begin{array}{l}5050-4900 \\
4890-4850\end{array}$ & $\begin{array}{l}5210-5170 \\
5150-5110 \\
5100-4790\end{array}$ \\
\hline $\begin{array}{l}\text { São Pedro de } \\
\text { Canaferrim }\end{array}$ & Simões 1997 & Carbón & ICEN-1151 & $6020 \pm 60$ & $4990-4800$ & $\begin{array}{l}5060-4770 \\
4750-4730\end{array}$ \\
\hline Los Barruecos & Inédita & Carbón & Beta- 159899 & $6060 \pm 50$ & $\begin{array}{l}5040-4900 \\
4890-4850\end{array}$ & $\begin{array}{l}5210-5170 \\
5070-4800\end{array}$ \\
\hline $\begin{array}{l}\text { Valada do } \\
\text { Mato }\end{array}$ & Diniz 2001 & Carbón & Beta- 153914 & $6030 \pm 50$ & $\begin{array}{l}4990-4840 \\
4820-4800\end{array}$ & $5050-4780$ \\
\hline
\end{tabular}

Tabla 3. Yacimientos con dataciones similares a Los Barruecos. Las calibraciones se realizaron con el programa OxCal 3.5., empleando los datos atmosféricos de Stuiver et al. 1998.

Dejando a un lado como la producción bibliográfica se ha encargado de afinar cada vez más la cronología de los conjuntos cerámicos con decoración impresa y retrasar éstos desde un Neolítico Tardío hasta la cronología antigua que propondremos más abajo, es destacable que nunca se haya poseído un repertorio tan variado de materiales cerámicos y sitios como el que hoy en día se nos ofrece. Recientemente, a propósito de la Vera, hemos señalado como la única opción metodológica que podíamos plantear para el estudio de las cerámicas neolíticas era la de asignar una cronología prudente a todas aquellas cerámicas impresas para las que no teníamos aún contextos estratigráficos (González Cordero y Cerrillo Cuenca 2001). El hecho de que manejemos por vez primera datos estratigráficos corroborados con dataciones absolutas y repertorios de materiales arqueológicos, nos hace ver como la seriación de materiales que se están proponiendo para todo el occidente peninsular, poco difiere de los procesos que analizamos en Extremadura; la consecuencia final es que resulta cuestionable mantener los vectores de difusión litoral-interior de largo recorrido temporal, y especialmente aquellas propuestas teóricas que avanzan la neolitización de las zonas periféricas a Portugal hasta momentos megalíticos (Kalb 1989).

La variedad de materiales y la posibilidad de establecer seriaciones entre determinados tipos y subtipos decorativos, dibuja un escenario de ocupaciones que se han mantenido como sincrónicas y características de un ámbito geográfico concreto como diferenciación cultural (Jiménez Guijarro 1998: 39), y que son más que discutibles, pues no sólo existen algunos elementos decorativos que varían zonalmente sino que pueden corresponder a distintos procesos no contemporáneos. Con la negación de la cultura material como elemento homogéneo que actúe como caracterizador crono-cultural preciso, debemos decir que nuestra opción teórica es considerar la trayectoria del Neolítico, en tanto proceso, como un discurso cultural de límites difuminados antes que como una estructura cerrada definida por relaciones entre aspectos socio-económicos y decoraciones cerámicas. Sin duda, el hilo conductor de todo este periodo es el de la aparición de las estrategias de producción, actividades orientadas a obtener un determinado recurso que en absoluto indican una economía de producción afianzada.

Todo ello supondría en definitiva cuestionar la tradicional secuencia tripartita del Neolítico en cualquiera de sus variantes geográficas, algo que ya se comenzaba a vislumbrar en Portugal donde en los últimos años se ha venido defendiendo una división en Neolítico Antiguo, Antiguo/Evolucionado, Medio y Final. En definitiva, se repiten corrientemente formas y decoraciones que no pueden seriarse únicamente a partir de paralelos, sino con la correcta comparación de cultura material, estratigrafías y dataciones absolutas, que en cada región concreta pueden experimentar peculiaridades, aunque bajo patrones generales muy similares.

Trazadas estas posiciones teóricas acerca de la validez de ciertos aspectos de la cultura material debemos establecer relaciones entre la datación presentada y la posibilidad de interacción con un teórico sustrato epipaleolítico y otro donde ya es- 
tán patentes las novedades económicas y tecnológicas del Neolítico. Desconocemos cuál fue el mecanismo de introducción de estas novedades en el seno de las primeras sociedades de tradición paleolítica del Holoceno. Ciertamente es necesario reunir más datos para reforzar las interpretaciones. $\mathrm{La}$ complejidad alcanzada en los concheros del Sado y el Muge y la perduración de estas sociedades mesolíticas hasta momentos del V milenio cal BC, cuando la presencia de sociedades productoras fuera de esos valles está ampliamente comprobada, plantea serias dudas en torno a la homogeneidad de todo el territorio y si algún tipo de recurso ideológico o socio-económico pudo verse involucrado en la "neolitización" de estas sociedades. Ello nos lleva a valorar que las innovaciones del Neolítico, independientemente de sus vías de introducción, puedan ser transgredidas o aceptadas dependiendo del desarrollo de la base poblacional. Habría que evaluar una vez más el papel que los grupos epipaleolíticos jugaron en la recepción y difusión de las ideas de la neolitización (Soares 1997: 604). Frente a esta alternativa, Zilhão (1997: 25) ha propuesto como la ausencia de evidencias del mesolítico en toda la zona de Lisboa y la aparición de ciertos yacimientos neolíticos en torno al 5500 cal BC plantea la opción de una colonización del terreno y la llegada de estrategias económicas novedosas en el registro arqueológico. Entre estas dos propuestas, por resumir, han girado las posiciones teóricas de los arqueólogos portugueses en los últimos años, situaciones que tampoco difieren en exceso de las planteadas por los españoles.

Sin duda, lo más indicado para comprender el modo en el que un paisaje comienza a experimentar un incipiente grado de complejidad en el que se han incluido síntomas de producción, es valorar los momentos previos a su introducción y resulta complejo establecer relaciones entre uno y otro paisaje, quizás porque en su momento de contacto no resultasen tan simples como pudiera pensarse. Hasta aquí apenas se tenían datos que hablaran de hábitats epipaleolíticos en el interior peninsular, aunque no deja de ser verdad que en los últimos tiempos se han dado pasos significativamente alentadores para salvar este panorama. Así, la cueva de El Conejar ha ofrecido ya dos dataciones epipaleolíticas idénticas de VIII milenio cal BC para una brecha caliza con industria lítica de tipo "languedocense" y carbones, que sitúan a 12 kilómetros de distancia y 2000 años de diferencia dos situaciones en principio distintas. Las dataciones $(8220 \pm 40 \mathrm{BP})$ han sido presentadas recientemente en las II Jornadas de Arqueología en Extremadura por los directores del Proyecto "Vendimia-Los primeros pobladores de Extremadura" y ofrecen sin duda una fecha post quem para el resto de evidencias de la cueva, como cerámicas impresas y granos de cereal. Pero El Conejar no es un hito aislado, en el Alentejo y en concreto en el yacimiento de Barca do Xerez Baixo se han datado industrias similares con una fecha de $8640 \pm 50 \mathrm{BP}$ (Almeida et al. 1999: 36).

Hay que señalar, además, que piezas como las laminitas de dorso abatido se incluyen dentro de un ambiente de tradiciones antiguas que continúan estando representadas en los momentos iniciales del Neolítico, circunstancia que no deja de anotarse en otros trabajos realizados en Andalucía Occidental (Acosta 1986: 148; Ramos et al. 1997: 686) y que es en definitiva una constante en el tránsito de uno a otro periodo en toda la Península. Pocos son los elementos de contacto que poseemos entre la cultura material de tradición epipaleolítica y la del Neolítico Antiguo, excepción hecha de ciertos elementos microlíticos característicos de sepulcros dolménicos de la región, y que aparecen en menor medida en contextos habitacionales, pero hoy por hoy resulta complejo ensayar una relación cronológica y cultural entre estas evidencias en sus respectivos contextos.

A partir de entonces no podemos precisar bien el modo en el que se produjo la consolidación del modo de vida productor en esta zona centro-occidental de la Península. Puesto que las dataciones y las comparaciones de estas nos emplazan al tránsito entre las facies de las cerámicas cardiales, testimonialmente representadas en El Conejar (Cerrillo Cuenca 1999: 115), y un momento del Neolítico Antiguo en el que se generalizan las cerámicas impresas con la técnica de boquique, posiblemente pueda situarse este proceso a lo largo de todo el $\mathrm{V}$ milenio Cal BC (Cerrillo Cuenca e.p). La continuidad de esta secuencia estaría representada por el Neolítico Medio y por la aparición de un elemento novedoso en el paisaje como es el megalitismo desde la primera mitad del IV milenio cal BC; a partir de entonces se desarrollan una serie de rasgos particulares del Suroeste que supondrán las bases de las ocupaciones calcolíticas durante el III milenio cal BC. Lejos de ver el proceso como una evolución directa desde las estructuras de producción más básicas del Neolítico Antiguo hasta el Neolítico Final, la secuencia cultural del Neolítico en Extremadura se presenta en determinados aspectos

T. P., 59, n. $^{\circ} 2,2002$ 
compleja y no puede valorarse estrictamente en términos evolutivos.

A lo largo del presente trabajo hemos tratado no sólo de presentar una nueva datación absoluta en el interior peninsular, sino también de apuntar una serie de conceptos teóricos que superen las limitaciones arqueográficas a las que se ha visto sometido el Neolítico en la construcción de su discurso. Con ello queda ya suficientemente demostrada la antigüedad del poblamiento al aire libre durante el Neolítico del interior, pero también la inclusión de espacios que hasta la fecha se suponían periféricos en la dinámica global de la neolitización peninsular.

\section{AGRADECIMIENTOS}

Los trabajos fueron financiados con una ayuda complementaria a la investigación del Ministerio de Educación, Cultura y Deporte.

Las tareas de campo no se hubieran podido llevar a cabo sin la ayuda entusiasta de D. Antonio Jiménez, alcalde del Excmo. Ayuntamiento de Malpartida de Cáceres, quien nos cedió los albergues municipales durante el transcurso de la campaña. Nuestros esfuerzos se vieron minimizados gracias a la colaboración de la Escuela Taller "Los Barruecos" y especialmente por su directora, Dña. Carmen Domínguez.

Debemos mencionar a los numerosos licenciados, y algún otro en trance de serlo, que colaboraron de manera activa en el transcurso de las excavaciones y cuyos nombres no podemos evitar incluir aquí: Víctor Manuel Cáceres, $\mathbf{M}^{\mathrm{a}}$ Soledad Gálvez, Elena Sánchez, Fco. Javier García, Miriam Alhambra, Juan José Pulido, $M^{a}$ Ángeles Cantillo, $\mathrm{M}^{\mathrm{a}}$ Dolores Mejías, Juan Barco, Miguel Hernández y Laura Muñoz. El estudio de materiales se está llevando a cabo en el Laboratorio de Arqueología de la Universidad de Extremadura gracias al trabajo desinteresado de Sara Vázquez, Jennifer Rol, Silvia Mancha y Fermina Acevedo.

Los datos de la excavación de El Conejar (Cáceres) aparecen aquí citados por cortesía del Dr. Eudald Carbonell, el Dr. Antoni Canals, ambos del Área de Prehistoria de la Universidad Rovira i Virgili, e I. Sauceda, co-directores del Proyecto "Vendimia-Los primeros pobladores de Extremadura".

Finalmente, los consejos y las valiosas sugerencias de la Dra. Bueno Ramírez del Área de Prehistoria de la Universidad de Alcalá de Henares, han contribuido a enriquecer significativamente el trabajo.

\begin{abstract}
ADDENDA
En la última campaña realizada en el verano de 2002, tuvimos la oportunidad de excavar en extensión buena parte de la ocupación de Neolítico Antiguo, lo que supone un total de $35 \mathrm{~m}^{2}$. El resultado ha sido la documentación de otro silo de características similares al ya conocido y una estructura de combustión. Estas estructuras y la relación entre ellas podrían suponer la existencia de un área dedicada al almacenaje y procesamiento de alimentos. Desde aquí agradecemos al Excmo. Ayuntamiento de Malpartida de Cáceres y especialmente a su alcalde, D. Antonio Jiménez, el haber subvencionado parte de esta campaña.
\end{abstract}

\section{BIBLIOGRAFÍA}

ACOSTA, P. 1986: "El Neolítico en Andalucía Occidental: Estado Actual".Homenaje a Luis Siret (1934-1984). Sevilla: 136-151.

ALMAGRO BASCH, M. 1962: Megalitos de Extremadu$r a$, II. Excavaciones Arqueológicas en España 4. Ministerio de Cultura. Madrid.

ALMAGRO GORBEA, M. 1977: El Bronce Final y el Periodo Orientalizante en Extremadura. Biblioteca Praehistorica Hispana 14. Madrid.

ALMEIDA, F.; MAURICIO, J.; SOUTO, P. y VALENTE, M. J. 1999: "Novas perspectivas para o estudo do Epipaleolítico do interior alentejano: noticia preliminar sobre a descoberta do sítio arqueológico da Barca do Xerez Baixo". Revista Portuguesa de Arqueología 2(1): 25-38

BOSCH GIMPERA, P. 1915-1920: "La cova del Boquique a Plasencia”. Anuari Institut Estudis Catalans VI. Barcelona: 513-516.

BUENO, P. 1994: “La necrópolis de Santiago de Alcántara (Cáceres). Una hipótesis de interpretación para los sepulcros de pequeño tamaño del megalitismo occidental". Boletín del Seminario de Estudios de Arte y Arqueología LX: 25-104.

- 2000: "El espacio de la muerte en los grupos neolíticos y calcolíticos de la Extremadura española: las arquitecturas megalíticas". En J. Jiménez Ávila y J. J. Enríquez Navascués (eds.): El megalitismo en Extremadura (Homenaje a Elías Diéguez Luengo). Extremadura Arqueológica VIII: 35-80.

BUENO, P.; BALBÍN, R. DE; BARROSO, R.; ROJAS, J.; VILLA, R.; FÉLIX, R. y ROVIRA, S. 1999: "Neolíti- 
co y Calcolítico en Huecas (Toledo). El túmulo de Castillejo. Campaña de 1998". Trabajos de Prehistoria 56 (2): 141-160.

CERRILLO CUENCA, E. 1999: "La cueva de El Conejar (Cáceres): avance al estudio de las primeras sociedades productoras en la penillanura cacereña". Zephyrus LII: 107-128.

- e.p.: "Estrategias productoras en la cuenca extremeña del Tajo (V y IV milenio Cal BC) I: cultura material y evolución". II Jornadas de Arqueología en Extremadura (Mérida, 2001).

CERRILLO MARTÍN DE CÁCERES, E. 1983: "Materiales de superficie de la cueva del Conejar, junto a Cáceres". Homenaje al profesor Martín Almagro Basch, Vol. II. Madrid: 37-44.

DELIBES DE CASTRO, G. y ZAPATERO MAGDALENO, P. 1996: "De lugar de habitación a sepulcro monumental: una reflexión sobre la trayectoria del yacimiento neolítico de La Velilla, en Osorno (Palencia)". Rubricatum 1. Actes I Congrés del Neolític a la Península Ibèrica. Formació i implantació de les comunitats agrícoles, Vol. 1: 337-348.

DÍAZ DEL RÍO, P. y CONSUEGRA, S. 1999: "Primeras evidencias de estructuras de habitación y almacenaje neolíticas en el entorno de la Campiña madrileña: el yacimiento de la "La Deseada" (Rivas-Vaciamadrid, Madrid)". II Congrés del Neolític a la Península Ibérica. Saguntum-PLAV, Extra-2: 251-257.

DINIZ, M. 2000: "O sítio neolítico da Valada do Mato, Évora: problemas e perspectivas". Revista Portuguesa de Arqueología 4(1): 45-59.

- 2001: "Uma datação absoluta para o sítio do Neolítico Antigo da Valada do Mato, Évora". Revista Portuguesa de Arqueología 4(2): 111-113

ENRÍQUEZ NAVASCUÉS, J. J. 1986: "Excavaciones de urgencia en la cueva de la Charneca (Oliva de Mérida, Badajoz)". Noticiario Arqueológico Hispánico 28: 824.

ESTREMERA, M. S. 1999: "Sobre la trayectoria del Neolítico Interior: Precisiones a la secuencia de la cueva de la Vaquera". II Congrés del Neolític a la Península Ibérica. Saguntum-PLAV, Extra-2: 245-250.

FERNÁNDEZ-POSSE, M. D. 1980: "Los materiales de la Cueva del Aire de Patones (Madrid)". Noticiario Arqueológico Hispánico 10: 41-64.

- 1982: "Consideraciones sobre la técnica de Boquique". Trabajos de Prehistoria 39: 137-159.

GONZÁLEZ CORDERO, A. 1996: "Asentamientos neolíticos en la Alta Extremadura". Rubricatum 1. Actes I Congrés del Neolític a la Península Ibèrica. Formació i implantació de les comunitats agrícoles, Vol. 2: 697 702.

- 1999a: "Datos para la contextualización del Arte rupestre esquemático en la Alta Extremadura". Zephyrus LII: 191-220.

- 1999b: "Comunidades neolíticas en los riberos Alto-
Extremeños del Tajo". II Congrés del Neolític a la Península Ibérica. Saguntum-PLAV, Extra-2: 531-540.

GONZÁLEZ, A.; ALVARADO, M. de; PIÑÓN, F y MUNICIO, L. 1988: "El poblado del Cerro de la Horca (Plasenzuela, Cáceres). Datos para la secuencia del Neolítico Tardío y la Edad del Cobre en la Alta Extremadura". Trabajos de Prehistoria 43: 87-102.

GONZÁLEZ, A.; CASTILLO CASTILLO, J. y HERNÁNDEZ HERNÁNDEZ, M. 1991: "La secuencia estratigráfica en los yacimientos calcolíticos del área de Plasenzuela (Cáceres)". I Jornadas de Prehistoria y Arqueología en Extremadura (1986-1990). Extremadura Arqueológica II: 11-26.

GONZÁLEZ CORDERO, A. y CERRILLO CUENCA, E. 2001: "El proceso de neolitización de la comarca extremeña de la Vera". Madrider Mitteilungen 42: 1-33.

GUTIÉRREZ PALACIOS, A. 1966: Miscelánea arqueológica de Diego Álvaro. Ávila.

JIMÉNEZ GUIJARRO, J. 1998: "La neolitización de la Cuenca Alta del Tajo. Nuevas propuestas interpretativas para el Neolítico de la Meseta". Complutum 9: $27-$ 47.

HOPF, M. 1966: “Triticum monococcum y Triticum dicoccum en el Neolítico antiguo español”. Archivo de Prehistoria Levantina XI: 53-73.

KALB, P. 1989: "O Megalitismo e a Neolitização no Oeste da Peninsula Iberica". Arqueología (Porto) 20: 33 48.

KUNST, M. y ROJO, M. 1999: "El Valle de Ambrona: un ejemplo de la primera colonización Neolítica de las tierras del interior peninsular". II Congrés del Neolític a la Península Ibérica. Saguntum-PLAV, Extra-2: 259270.

MALUQUER DE MOTES, M. 1957: Excavaciones Arqueológicas en el Cerro del Berrueco (Salamanca). Acta Salmanticensia, XIV(1). Salamanca.

MUNICIO, L. 1988: "El Neolítico en la Meseta Central Española”. En P. López (coord.): El Neolítico en España. Catedra. Madrid: 299-239.

MUNICIO GONZÁLEZ, L. y RUIZ-GÁLVEZ, M. L. 1986: "Un nuevo yacimiento Neolítico de la Meseta Norte: las cerámicas decoradas de la Cueva de la Nogaleda (Villaseca, Segovia)". Nvmantia II: 143-157.

OOESTERBECK, L. 1993: "Nossa Señora das Lapas: excavation of prehistoric cave burilas in central Portugal". Papers from the Institute of Archaeology 4: 49-62.

PAN, I. del 1917: "Exploración en la cueva prehistórica del Conejar (Cáceres)". Boletín de la Real Sociedad Española de Historia Natural XVII: 185-190.

RAMOS, J.; LAZARICH, M.; CASTAÑEDA, V.; PÉREZ, M.: MONTAÑÉS, M.; BLANES, C.; LOZANO, J. M.; HERRERO, N.; GARCIA, M. E. y AGUILAR, S. 1997: "Los inicios de la economía de producción en la Bahía de Cádiz”. En A. Rodríguez Casal (ed.): O Neolítico Atlántico e as orixes do Megalitismo, Santiago de Compostela: 677-689.

T. P., 59, n. ${ }^{\circ} 2,2002$ 
RIVERO DE LA HIGUERA, M. C. 1972-1973: "Materiales inéditos de la Cueva de Boquique. Datos para una nueva sistematización de la Edad del Bronce en Extremadura". Zephyrus XXIII-XXIV: 101-130.

SANCHES, M. J. 2000: "Reflexões sobre o povoamento do Neolítico Inicial do Norte de Portugal $\left(\mathrm{VI}^{\circ}-\mathrm{IV}^{\circ} \mathrm{Mil}\right.$

A.C.)". Neolitização e megalitismo da Península Ibérica. Actas do $3^{\circ}$ Congresso de Arqueología Peninsular, Vol. III: 181-201.

SAUCEDA, M. I. 1984: "La cueva del Conejar (Cáceres). Una muestra de los materiales recogidos en 1981". Norba 5: 47-58.

- 1986: "Primeros avances sobre el Calcolítico en Extremadura: Los Barruecos, Malpartida de Cáceres (Cáceres)". Norba 7: 17-23.

- 1991: "La secuencia cultural de "Los Barruecos". Malpartida de Cáceres (Cáceres)". I Jornadas de Prehistoria y Arqueología en Extremadura (1986-1990). Extremadura Arqueológica II: 27-44.

- 2001: Pinturas y grabados rupestres esquemáticos del Monumento Natural de Los Barruecos. Malpartida de
Cáceres. Memorias 2. Publicaciones del Museo de Cáceres. Mérida.

SIMÕES, T. 1999: O sítio neolítico de São Pedro de Canaferrim, Sintra. Contribuções para o estudo da neolitização da península de Lisboa. Trabalhos de Arqueología 12. Lisboa.

SOARES, J. 1997: “A transição para as formações sociais neolíticas na costa sudoeste portuguesa”. En A. Rodríguez Casal (ed.): O Neolítico Atlántico e as orixes do Megalitismo. Santiago de Compostela: 587-608.

STUIVER M.; REIMER, P. J.; BARD, E.; BECK J.W.; BURR G.S.; K.A.; KROMER B.; McCORMAC, G.; VAN DER PLITCH J. y SPURK M. 1998: "INTCAL98 Radiocarbon Age Calibration, 24000-0 cal BP”. Radiocarbon 40 (3): 1041-1083.

ZILHÃO, J. 1997: "Maritime pioneer colonisation in the Early Neolithic of the west Mediterranean. Testing the model against the evidence". Poročilo o raziskovanju paleolitika, neolitika in eneolitika v Sloveniji XXIV, Neolitske študije. Liubliana: 19-42. 